\title{
JOSÉ ANTONIO MARINA: EN BUSCA DE UNA FUNDAMENTACIÓN PRÁCTICA DE LA ÉTICA
}

\author{
Javier Sánchez Pachón \\ I.E.S. Marqués de la Ensenada (Haro, La Rioja)
}

\begin{abstract}
RESUMEN: Mostraremos la teoría ética de J. A. Marina según cuatro perspectivas. La primera es la consideración de la inteligencia humana como una herramienta capaz de crear posibilidades, proyectar y mejorar lo que antes había; siendo la ética una de las grandes creaciones de esta inteligencia humana junto con la ciencia y el arte. La segunda se refiere a la fundamentación inductiva de la ética en la que se propone que no son los principios morales los que justifican los hechos, sino los hechos los que permiten generalizaciones éticas sobre las cuales se fundan los principios morales. La tercera concluye que los deberes y también los derechos dependen de una serie de ganchos trascendentales o axiomas éticos que los justifican: Dios, la naturaleza, la dignidad... El análisis ético-histórico determinará cuáles son mejores. La cuarta considera que la ética es intersubjetividad; la condición social del ser humano dirige nuestra búsqueda a la construcción de una ética universal constituyente como la de una gran obra en permanente construcción y reforma.
\end{abstract}

Palabras clave: Ética, creación, fundamentación, gancho, intersubjetividad.

ABSTRACT: We will show J. A. Marina's ethical theory from four different points of view. The first one is the consideration about human intelligence as a tool, which is able to create opportunities, design and improve what there was before; being the ethics one of the greatest creations of human intelligence together with science and arts. The second one is about the inductive ethics foundation in which moral values don't justify the facts, but the facts support ethical generalizations which are based on moral principles. The third one concludes that both duties and rights depend on some transcendental hooks or ethical axioms that justify them: God, nature, dignity... The ethical-historical analysis will determine which ones are best. The fourth one considers that ethics 
is intersubjectivity; the social human condition leads to our search to the construction of a universal ethics like one of the greatest actions on permanent construction and reform.

Keywords: Ethics, creation, foundation, hook, intersubjectivity.

\section{Planteamiento}

La ética como reflexión sobre la moralidad y los códigos de comportamiento no ha podido nunca desprenderse del interés por su fundamentación, cosa lógica si pretendemos responder no sólo a lo que debemos hacer, sino también a por qué hemos de hacerlo. La eudaimonía aristotélica o el imperativo categórico kantiano han sido las principales vías de fundamentación de la moralidad por las que transitan las teorías éticas. En los últimos tiempos, sin embargo, la felicidad como último concepto filosófico y ético se ha visto desplazado por el concepto de la justicia; de forma que las dos vías mencionadas bien podrían haberse convertido en las de éticas de la felicidad y éticas de la justicia, dos vías que discurren paralelas y además parejas porque no puede avanzar sin mirarse de reojo, ni es posible que la una progrese sin que la otra lo haga en igual medida. Y es que lo que está en el fondo de este dualismo ético es ese rostro jánico de la moral; la doble cara que la ética presenta: por un lado ha de conseguir la felicidad del individuo, y por el otro ha de procurar la sociedad justa sin la que es imposible aquella. Tanto es así que desde la aparición de la obra de J. Rawls es imposible hablar de ética sin colocar en su edificio la justicia como piedra angular. "Este es el gran reto cultural del momento; fomentar un modo de ser sujeto capaz de superar el concepto de libertad desvinculada, y de encontrar nuevas fuentes de posibilidad -es decir de esperanza- en la relación con los demás"”.

Sin embargo, en la fundamentación de la ética se arrastra desde tiempos ancestrales el problema de mayor envergadura filosófica: se trata de la imposibilidad de justificar el deber ser a partir del ser. Como Hume denunciara en su falacia naturalista, del ser no podemos inferir nada sin incurrir en una falacia, en un supuesto, en un presunto deber ser surgido de nuestra natural tendencia al orden y a causalizar los hechos. Sólo la aparición de la ética aplicada ha posibilitado otro estatus para la ética y para su fundamentación, propiciando al menos un momento aristotélico, en el que la observación y la casuística representan, si no un punto de llegada, sí uno de partida para que la vocación ética de aplicarse al comportamiento y de servir de justificación a las vías morales,

1. MARINA, José Antonio, Las culturas fracasadas; el talento y la estupidez de las sociedades, Anagrama, Barcelona, 2010, p. 145. (A partir de ahora, utilizaremos las siglas LCF al referirnos a esta obra). 
surta su efecto. En este sentido, la ética aplicada ha supuesto un respiro y un cierto olvido de la falacia naturalista.

La ética de J. A. Marina representaría un intento si no de superar, sí de integrar por una parte el doble objetivo ético del individuo y de la sociedad y por otra la justificación de las normas a partir de unos criterios de valoración extrínsecos a ellas mismas y que se encuentran en el estudio de las sociedades que los han admitido. Todo descansa para él en el concepto de inteligencia. No es momento ahora de exponer con detenimiento la visión de la capacidad intelectiva humana, que aparece ya en sus primeras obras como Teoría de la inteligencia creadora, simplemente diremos que la entiende como la capacidad de salir bien parado de la situación en la que estamos metidos; "defino inteligencia como la capacidad de dirigir bien el comportamiento, captando, elaborando y produciendo información "2. Ahora bien, la inteligencia es una herramienta de cada individuo pero que se forma en la sociedad; por eso podemos hablar de una inteligencia compartida. No hay inteligencia humana fuera de la sociedad, como ya anunciara Aristóteles en su afirmación del ser humano como animal político; de forma que igual que podemos hablar de individuos inteligentes o estúpidos según la manera que tienen de solucionar sus problemas vitales, todos sus problemas: económicos, emocionales, familiares, sociales, laborales... podemos y debemos hablar también de sociedades inteligentes o estúpidas según su capacidad para solucionar los problemas de toda la vida: las relaciones entre los individuos, entre los sexos, entre el poder político y los ciudadanos o súbditos, entre la religión y la política, etc.

Siendo la ética una de las mayores y más representativas creaciones humanas junto con la ciencia y el arte, evaluar las sociedades, valorarlas, ensalzarlas o censurarlas será tarea obligada desde un análisis ético. La mejor herramienta de la inteligencia para resolver los problemas de la inteligencia es la moral. Es más, una sociedad inteligente, buena, es la que resulta bien valorada no por sus ciudadanos sino en virtud de unos criterios derivados de la solución inteligente de los problemas. Nos acercamos así a una fundamentación inductiva de la ética en la que son los hechos los que determinan la bondad o maldad de una trayectoria moral; no son los principios morales los que justifican los hechos, sino los hechos los que permiten generalizaciones éticas sobre las que se fundan los principios morales. Se trata de aprovecharnos de la experiencia de la humanidad.

La defensa de su concepto de inteligencia y de la fundamentación inductiva de la ética le lleva a Marina a estudiar las bases sobre las que se asienta la vida del ser humano. Un ser que es radicalmente distinto a todos los seres que le rodean, fundamentalmente porque puede ser su propio autor. Los animales nacen ya con el libro de instrucciones, nosotros, si lo tenemos, lo tenemos en

\section{LCF 21.}


blanco y necesitamos escribirlo. El análisis de esas bases es fundamental porque son las que nos posibilitan ingeniar, crear, inventar formas de vida buenas (sigue en esto Marina la tradición ética española de Ortega, Zubiri o Aranguren). De ahí que la ética tenga tanto que ver con el arte o con la ciencia como formas de creación inteligente o si se quiere exclusivamente humana.

$\mathrm{Y}$ aquí es donde encontramos la mayor contribución de Marina, a quien le hubiera gustado encontrar un fundamento más técnico que la mera enunciación de procesos históricos de liberación que estudia sobre todo en su libro de $L a$ lucha por la dignidad. Si la tesis de Marina sobre el fundamento del deber es la consecución de derechos, la del fundamento de la ética es que estrictamente hablando no existe, a no ser que recurramos a la definición del ser humano como un ser inteligente y social. Y esto es decir poco o nada. Hay que volver nuestra mirada a las cosas que hemos hecho y evaluarlos. Así pues, la fundamentación ética no se soluciona sólo con admitir que el hombre es racional. Bien, es racional y ¿qué? habrá que vestir a esa racionalidad de hechos que lo demuestren. Digamos que a la racionalidad hay que añadirle un adjetivo para que sepamos a qué razón nos estamos definiendo, en el caso de Marina podríamos decir que es la razón histórica la que encuentra en los mismos hechos la fundamentación de la ética. En la ética discursiva, es la razón dialogante la autoridad legítima y esto porque, como ya hemos dicho, la realidad empírica no puede traspasar los límites de los hechos. Del ser no podemos pasar al deber ser, como denuncia la falacia naturalista. Necesitamos en la razón discursiva o comunicativa, por el contrario, una razón que sea anterior a la experiencia, por decirlo en términos kantianos, una razón a priori, una fundamentación que por fuerza ha de ser trascendental en la fundamentación de los juicios morales: "Ios juicios del deber moral no pueden derivarse de constataciones empíricas porque de los hechos empíricos no puede surgir obligación alguna"s.3.

Si queremos encontrar la respuesta a por qué hay que actuar así, hemos de acudir a las cosas mismas, como diría Husserl, "en la confianza de que las cosas pueden dar razón de su ser distinta de la mera explicación genética" ${ }^{\prime 4}$, a los hechos mismos para analizarlos y mostrar cómo han contribuido al progreso moral o por el contrario cómo han significado o pueden significar un regreso a la selva. Es decir, para hacer de la ética una ciencia rigurosa necesitamos aplicarle también a ella el método hipotético deductivo. De manera que en esto podríamos hacer un paralelismo entre Kant, cuando nos invita en filosofía a aplicar el método que tan buenos resultados está dando en la ciencia natural, y Marina, cuando nos insta a buscar una fundamentación práctica para la ética,

3. CORTINA, Adela, Ética mínima; Tecnos, Madrid 2008, p. 107.

4. VALCÁRCEL, Amelia, "Valor», en Diez palabras clave en ética, Verbo Divino, Pamplona 1994, p. 415. 
una investigación inductiva para ver las cosas que han funcionado mejor gracias a que han sido invenciones realizadas sobre lo que antes no existía. Esto nos mete de lleno en un proyecto ético que Marina llama período ético constituyente porque la ética es la ciencia buscada y nunca hallada que está en formación permanente. Es un edificio sobre el que vamos construyendo poco a poco nuevos pisos y dándoles nuevas utilidades.

Hay, además, según esta pretendida fundamentación una valoración del progreso moral como factor determinante de justificación porque "si mi capacidad para resolver problemas, para crear, para dirigir bien mi vida, no depende sólo de mi inteligencia y esfuerzo, sino de la inteligencia de la sociedad en la que viva, me enfrento -nos enfrentamos- a un asunto de indiscutible trascendencia del que va a depender mi futuro y el de los míos" ${ }^{\prime \prime}$. Podemos calificar de progreso moral aquel comportamiento social que aumenta las posibilidades de realización de cada miembro y mejora la consecución de fines objetivos. "Los estudios transculturales nos muestran una coincidencia en las virtudes morales propuestas por las diferentes culturas, que corrobora la dirección evolutiva que he señalado". . Marina entiende aquí progreso moral al modo en el que lo hace Kohlberg en primer lugar como cognitivista que estudia la formación de la conciencia moral, pero sobre todo al modo como lo hace Habermas. Ambos nos remiten al aumento del capital social como factor objetivo y medible de las sociedades. El capital social se traduce finalmente en la adquisición y asentamiento de las virtudes públicas que a su vez tienen efectos individuales o subjetivos como es el aumento de la felicidad de los miembros. Pues bien, la cultura es para Marina, entre otras cosas, un ensayo de soluciones a los problemas de convivencia y en ese ensayo y error hay un efecto de progreso aunque en moral también naveguemos en zigzag. Marina enumera los nueve grandes problemas morales que las sociedades han tenido y tienen que ir resolviendo: el valor de la vida, la distribución de los bienes, el poder, la relaciones con la comunidad, la solución de conflictos internos, el sexo, el cuidado de los débiles, el trato con los extranjeros y la religión. "El primer paso tiene que ser elaborar una historia universal de la cultura que explique cómo se han resuelto los nueve problemas fundamentales... que constituya una memoria colectiva de la humanidad"n. Según Habermas, el cambio, la evolución social la producen dos aprendizajes principales: el aprendizaje técnico y el aprendizaje moral. Al decir aprendizaje queremos decir racionalización: cancelación de aquellas reacciones de violencia que se han acomodado inadvertidamente en las estructuras comunicacionales y que, valiéndose de barreras, impiden dirimir conscientemente y regular de modo consensual los conflictos. Para Habermas hay diver-

5. LCF 31.

6. LCF 169.

7. LCF 82. 
sos estadios de la evolución social de las normas, igual que lo hay en la evolución de la conciencia en Kohlberg: estadio preconvencional, convencional y posconvencional. Todos tienen una lógica de desarrollo, esta lógica no es otra que la acción comunicativa, de forma que la conciencia moral viene determinada por la competencia interactiva de un nivel. La conciencia moral es la capacidad para resolver conflictos morales; en definitiva pues, una conclusión que podríamos sacar es que cuanto más desarrollada está una sociedad y mayor capacidad tiene para resolver sus conflictos mediante el diálogo, disfruta de una mayor conciencia moral. Una moral alta es signo de una racionalidad y conciencia moral alta.

Habermas señala algunas etapas en esta evolución de la conciencia moral: en las primeras etapas, las de las civilizaciones arcaicas, la imagen del mundo es mítica y la justificación de las normas es narrativa y además particularista porque no pretenden una validez universal. Con las civilizaciones desarrolladas (filosofía griega, cristianismo) toman cuerpo los argumentos que pretenden ya ser universales. Este carácter de validez universal será a partir de ahora una característica de lo moral. Los juicios morales no se imponen ahora dogmáticamente sino que tienen que ser avalados con argumentos y justificados racionalmente. En las últimas etapas se recurre al principio formal de la razón.

Esta teoría del progreso moral, aparte de ser cuestionada, pues donde algunos ven progreso, otros ven inmovilismo o retroceso, es completada con otras teorías como la de Carol Gilligan, seguidora de Kohlberg, para quien el desarrollo de la conciencia moral ha de contar con otros componentes además de la justicia, como son la compasión y el cuidado. Esto nos introduce en el gran tema que entre nosotros desarrolla, por ejemplo, Adela Cortina con La razón cordial: "alcanzar la madurez moral no consiste sólo en llegar a ser justo, sino también en lograr ser compasivo y capaz de responsabilizarse de aquellos que nos están encomendados"s. Así es que el desarrollo social de la conciencia moral sucede cuando son dos voces las que se escuchan: la voz de la razón y la voz del corazón.

Con todo, la ley del progreso ético de la sociedad le lleva a Marina a considerar que, al igual que hay muchas civilizaciones, deberíamos tender a una civilización que se rigiera por valores universales, valores que han pasado el banco de pruebas de la historia, y al igual que hay muchas éticas, deberíamos tender a una ética mundial, porque la ética es la mejor herramienta de la inteligencia social " por poner un ejemplo, nunca han estado tan protegidas las religiones -todas- como desde que se aceptó el principio ético laico del derecho a la libertad de conciencia"'s.

8. CORTINA, Adela, Ética de la razón cordial, Ediciones Nobel, Madrid, 2009, p. 150.

9. LCF 170. 
El proceso evolutivo de la ética desemboca también en un nuevo sujeto moral capaz de desmontar el mito de la mano invisible del Estado del que hablara A. Smith, según el cual sólo el interés puede solucionar los problemas de convivencia. O incluso en un sujeto más allá del propuesto por Rawls en su velo de ignorancia. Para Marina estas teorías no responden a la pregunta fundamental de la ética que es iy por qué debo hacer lo que debo?: "el individualismo ha evaporado los procedimientos de coacción suave que se ejercían a través de sentimientos: el sentimiento del deber, la compasión, la vergüenza, la culpa, la gratitud, la admiración y la indignación ante la injusticia"10. Pero, sobre todo, hemos de pensar que si la inteligencia social ha servido para solucionar problemas de convivencia, ¿por qué no había de continuar haciéndolo cada vez mejor? La esperanza en el aumento del capital social es también la consecuencia de la confianza en el nuevo sujeto moral, cuya definición más avanzada como ser humano es que es un animal inteligente dotado de dignidad, y de esa dignidad se derivan los derechos humanos.

Y es que "para evaluar los sistemas morales hay que acudir a la experiencia práctica de la humanidad. Como dice Hans Albert, un prestigioso filósofo de la ciencia: En cualquiera de los casos, a la hora de fijar un criterio para la verificación de los sistemas éticos, habrá que poner en primer plano la satisfacción de las necesidades humanas, el cumplimiento de los deseos humanos, la eliminación del sufrimiento humano innecesario, la armonización de las aspiraciones humanas intersubjetivas e intrasubjetivas; hechos, en todos los casos, controlables sobre la base de experiencias humanas" ${ }^{\prime \prime 1}$. Aunque las normas tienen un origen diferente según veremos ahora, todas tienen, pues, el mismo criterio de evaluación que es el bien que han posibilitado y por tanto, el poso de humanidad que han legado al proceso evolutivo de la moral humana.

En efecto, la inteligencia social ha generado ineludiblemente normas para la convivencia, esas normas pueden ser por una parte espontáneas o jerárquicas y por otra racionales o no racionales; la combinación de estos tipos nos ofrece cuatro maneras de concebir las normas según sean espontáneas racionales como las normas comerciales, jerárquicas racionales como las normas legislativas, espontáneas no racionales, el tabú del incesto por ejemplo, y jerárquicas no racionales como las religiones. Es claro que aunque el origen sea el apuntado, la evolución de las normas y de las sociedades hace que puedan ir variando. Y no es el origen lo importante, sino aquello en lo que han deparado y a lo que han dado lugar: "la crítica cultural ha de ser inductiva. La historia es el banco de pruebas de la humanidad. Hemos sido nuestras propias cobayas. Un mínimo reconocimiento a las victimas del horror de la historia es intentar apren-

10. LCF 179.

11. ALBERT, Hans, Ética y metaética, Cuadernos Teorema, Valencia, 1978, p. 46, en LCF 151. 
der de su desdicha. Y un mínimo reconocimiento a los que mejoraron la condición humana nos obliga a clarificar y prolongar su acción"12.

\section{La felicidad personal y la felicidad política. La fundamentación práctica}

Para Marina nuestro objetivo de ser felices o de tener derechos, que es algo que todo ser humano desea, sólo es realizable en comunidad. La autonomía o la libertad se logran mancomunadamente. La definición de los griegos del hombre como animal político parece irrefutable. Lo que ocurre es que la polis nunca nos la dan hecha del todo, es algo que tenemos que seguir construyendo y eso lo podemos hacer bien o lo podemos hacer mal. Una fundamentación de la ética consistirá en separar precisamente los buenos experimentos de los malos. La ética es así la gran creación humana para ser feliz, creación que se funde o se manifiesta en la política. Ética y política son las grandes creaciones de la inteligencia que llega a diseñar un orbe nuevo para una nueva humanidad.

La inteligencia está precisamente para vencer y superar lo que las cosas son por lo que descubrimos en ellas. El hombre es el único animal que proyecta, o como decía Sartre citando a Ponge: "el hombre es el porvenir del hombre" ${ }^{\prime \prime 3}$. Neurología y sociedad nos definen. Antes de nosotros ya existía la realidad, pero nosotros la hemos transformado: hemos sido capaces, hasta ahora de forma misteriosa, de enseñar un lenguaje que nos relaciona, comunica y en el que aprendemos el mundo; hemos conseguido colaboraciones en grupos muy extensos, hemos controlado impulsos muy fuertes por medio de las coacciones sociales, hemos anticipado el futuro... Sin embargo, esto no ha sido gratuito. A fuerza de debatirnos entre el individualismo y la socialización, hemos acabado por convivir con esta contradicción humana que Kant señalaba como la insociable sociabilidad del ser humano: "El medio de que se sirve la Naturaleza para lograr el desarrollo de todas sus disposiciones es el ANTAGONISMO de las mismas en sociedad... Entiendo en este caso por antagonismo, la insociable sociabilidad de los hombres, es decir, su inclinación a formar sociedad que, sin embargo, va unida a una resistencia constante que amenaza perpetuamente con disolverla"14.

Los ifalux, una tribu de Melanesia, desconfía de la felicidad personal porque es la antesala de la despreocupación por los asuntos sociales. Piensan que quien se siente satisfecho con su suerte, su situación o sus propiedades, se va a despreocupar de la vida en común. El bienestar es egoísta y la supervivencia del grupo está por encima de los individuos. Salvando la distancia, la sociedad del bienestar ha producido individuos cómodamente instalados que no dudan de

12. LCF 162.

13. SARTRE, J. P., El existencialismo es un humanismo, Barcelona, Edhasa, 1989, p. 27.

14. KANT, I., La idea de una historia universal en sentido cosmopolita. FCE, México, 2006, p. 46. 
sus derechos porque creen que han estado ahí desde siempre o que han crecido como los champiñones. Necesitamos seguir construyendo el orbe o el mundo en el que queremos vivir y eso exige no bajar la guardia nunca.

El hombre es el animal que promete. Es decir el hombre es el ser que puede y quiere dominar sus instintos, digamos su urgencia, a favor de un bien posterior. De forma que la libertad está al final y no al principio del proceso. El niño aprende la libertad obedeciendo a otro y no obedeciendo a sus impulsos. La disciplina y la humanidad son inseparables ${ }^{15}$.

Por otra parte, el individuo y también la autonomía es algo relativamente nuevo porque el hombre nace integrado en un grupo en el que la responsabilidad de los actos individuales queda a veces diluida. Cuando el ser humano supera el instinto, tiene que inventarse nuevas instrucciones para vivir según sus posibilidades, no lo olvidemos y por encima de sus realidades. El ser humano ha ido descubriendo valores, proponiendo y rechazando. La historia de estos valores es la historia de la ética y la fundamentación de la ética descansa en la evolución de estos valores. Visto así, tenemos que la historia de la ética tiene muchos protagonistas, unas veces individuos extraordinarios, otras veces grupos de individuos más o menos anónimos.

La meta de la sociedad y la del individuo coinciden: la felicidad. Pero no se puede dar ésta sin la colaboración de las otras dos. Son metas que coinciden en el espacio y en el tiempo; porque, como decían los ilustrados, nadie se une a los otros para ser desdichado. La similitud entre el pensamiento ilustrado y la necesidad de integrar la felicidad personal en la felicidad social que Marina pretende es muy clara, y lo veremos más adelante cuando proponga los ideales de la Ilustración como uno de los momentos estelares del progreso moral.

Lo que vamos a hacer en las páginas siguientes es esta crónica de la invención moral según la cual la inteligencia creadora, que Marina estudia en sus primeros libros, se va a desplegar en una de sus más complejas e ingeniosas creaciones: el afán solucionador de conflictos, es decir la ética. Este afán es algo universal, aunque las soluciones sean individuales. ¿Por qué hay ética?, porque hay seres inteligentes y ipara qué la ética?, para solucionar los problemas. Los problemas son casi los mismos desde el origen de los tiempos. Las soluciones no. Pensemos por ejemplo en los problemas de la moral sexual; son básicamente los mismos, pero cuentan con múltiples soluciones que van desde la poligamia a la monogamia.

Aparece, pues, según Marina un dinamismo solucionador que da origen a la ética, pero también un dinamismo emancipador y reivindicativo como si el ser humano pretendiera que la solución ensayada valiera para siempre. Es el dina-

15. Marina ha estudiado ampliamente la influencia social en la formación del comportamiento voluntario en su libro El misterio de la voluntad perdida, Anagrama, Barcelona, 1998. 
mismo de los valores, la capacidad que tienen de fijarse en las sociedades. El ser humano percibe que las cosas pueden ser siempre de otra manera. Es la necesidad de la utopía. Marina cree que la hipótesis del derecho natural, aunque errónea en sus principios, puede ser muy útil porque "las reivindicaciones morales buscan el reconocimiento de un derecho, el acceso a un valor merecido, la abolición de una presunta injusticia. Ponen de manifiesto una carencia indebida"16.

Los grandes proyectos que dirigen la acción moral, que ensayan soluciones y que abren nuevos caminos son: solucionar, emancipar y elevar. Hay pues un deseo solucionador y un deseo emancipador. Las tesis que se defienden en $L a$ lucha por la dignidad son las siguientes:

"Tesis primera: La humanidad, movida por deseos imperiosos y contradictorios, se ha dirigido siempre a una meta que se designa con términos amplios, vagos e inevitables, como felicidad o justicia.

Tesis segunda: Cuando los seres humanos se libran de la miseria, de la ignorancia, del miedo, del dogmatismo y del odio -elementos claramente interrelacionados- evolucionan de manera muy parecida a la racionalidad, la libertad individual, la democracia, las seguridades jurídicas y las políticas de solidaridad.

Tesis tercera: La humanidad por distintos y convergentes caminos ha descubierto que el modo más seguro y eficaz de conseguir la felicidad y la justicia es afirmando el valor intrínseco de cada ser humano.

Tesis cuarta: Ese valor supremo ha encontrado su mejor definición operativa en el concepto de derechos prelegales (derechos subjetivos, innatos, derechos morales o como quieran denominarlos) que a su vez se han concretado en los Ilamados derechos humanos.

Tesis metodológica: La historia de la lucha por la dignidad es una fundamentación práctica de la ética"17.

Vamos a explicar brevemente el sentido de estas tesis que los análisis de los hechos históricos pretenden demostrar:

Tesis 1. El ser humano se define como un ser inacabado y un ser contradictorio y paradójico, es un egoísta social o, repetimos con Kant, un ser socialmente insociable; pues bien, la ética trata siempre de resolver esas contradicciones. El hombre busca su felicidad, pero sólo la encuentra junto a los otros. La justicia nace en este ámbito.

16. MARINA, J. A., La lucha por la dignidad, Anagrama, Barcelona, 2000, p. 24. (A partir de ahora, usaremos LLPD para referirnos la obra citada).

17. LLPD 27. 
Tesis 2. existe el progreso moral, de forma que, con Bobbio, podemos decir que "es un signo del progreso moral de la humanidad el hecho de que haya una historia de los derechos humanos ${ }^{\prime \prime 1}$.

Tesis 3. Afirma el valor de cada ser humano. A lo largo de la historia hemos valorado sobre todo la nación, el pueblo, la raza, Dios, la patria o el grupo, pero parece que desde el Renacimiento (recuérdese el discurso sobre la dignidad humana de Picco de la Mirándola) hasta la Modernidad vamos hacia la defensa del valor de cada individuo: "pero los seres racionales se denominan personas porque su naturaleza ya los señala como fines en sí mismos... y siendo un objeto de respeto, son fines objetivos, es decir, cosas cuya existencia es en sí misma un fin"119. De tal forma que eso se convierte a la postre en el fundamento de la convivencia. Desde hace algún tiempo a ese valor se le designa con el nombre de dignidad.

Tesis 4. La materialización de los derechos del hombre está sobre todo en dos declaraciones: la de 1789 y la de 1948. Son los grandes momentos de la historia de la ética.

Tesis metodológica. La historia es el banco de pruebas de las soluciones morales. Necesitamos no sólo fundamentar la ética en el plano teórico, sino acudir al laboratorio de la historia para ver si las soluciones adoptadas han funcionado; para ver también si el fundamento es suficientemente sólido. Sería estúpido no tener en cuenta todos los "experimentos" morales para evaluarlos y ver lo que nos muestran.

De manera que para Marina, según ya anunciábamos, la invención ética guarda un gran paralelismo con la invención científica; por eso, ha de someterse también a sus mismas reglas y a sus mismos criterios. Los tanteos, intentos o experiencias de nada servirán si no van seguidos de un segundo nivel crítico en el que se solucione, se asegure y se compruebe. Necesitamos verdades morales que nos permitan construir encima. Necesitamos una epistemología de la ética. Según Marina, también la biografía de las invenciones morales nos proporciona simultáneamente un criterio de justificación. Partimos de los hechos, para explicarlos montamos una teoría sugerida por ellos mismos y después necesitamos confirmarla o negarla volviendo a los hechos que nos la han sugerido: contrastar, falsar o verificar. La experiencia de millones de personas, el dolor, la alegría, el éxito, el seguimiento, la admiración, los errores, el escarmiento hay que tomarlos como el fundamento de la ética.

Así pues, si recapitulamos, diremos que el ser humano desde que quiere vivir por encima de sus realidades proyecta un mundo que puede ser de otra

18. BOBBIO, N., El tiempo de los derechos, Sistema, Madrid, 1991, p. 11.

19. KANT, I., Fundamentación de la metafísica de las costumbres, Santillana, Madrid, 1996, p. 51. 
manera. En definitiva, pretende la solución de conflictos que le plantea su paradójica condición de ser socialmente insociable: esta solución pasa en general por salir de la selva donde impera la ley de la violencia y acercarse a una situación asentada en la ley y el derecho. Este es un lento y largo camino cubierto de éxitos y fracasos. La meta actual de este camino es la dignidad del ser humano, el valor intrínseco de cada persona. Por eso, fundamentar la ética es hacer la historia de la dignidad. El conocimiento ético irá unido a la experiencia ética o, mejor, se verá contrastado, verificado o falsado por ella.

Si existe una estrecha relación entre la felicidad objetiva o individual y la felicidad objetiva o social, la fundamentación ética tiene que recorrer ambos aspectos porque el ser humano se ha movido siempre entre esas dos aspiraciones: la de la felicidad y la de la justicia: "la búsqueda de la justicia es la eterna búsqueda de la felicidad humana. Es una felicidad que el hombre no puede encontrar en sí mismo, y por ello, la busca en la sociedad. La justicia es la felicidad social, garantizada por un orden social"20. Nuestras vidas pública y privada aparecen unificadas en esta disciplina que es la ética. Muchas veces la ética política y la privada aparecen en mundos distintos cuando en realidad estamos hablando de lo mismo. Platón en esto fue un maestro porque unificó la triada de conceptos saber, virtud y felicidad y los hizo posibles en su República. En efecto, según Marina, relacionar felicidad y justicia no es ninguna ingenuidad, porque aunque la justicia no produce inexorablemente la felicidad personal es la mejor garantía de que suceda. De ahí que haya que hablar en ética de dos tipos de felicidad, la subjetiva, el bienestar personal y otra felicidad objetiva, política y social que se concreta en el marco deseable para vivir y para que se realice ese bienestar personal.

Por eso, La lucha por la dignidad va a ser una fundamentación de la felicidad política, porque sin ella no es posible la felicidad personal. Es decir, la política es una condición necesaria, aunque no suficiente, para la felicidad personal y por consiguiente para la invención moral. Y aquí es donde entra la teoría de los ganchos trascendentales, una teoría genuina de Marina según la cual, en ética como en otras disciplinas, justificamos una afirmación enganchándola a un nivel superior, a veces simplemente un postulado, una especie de fundamento que podríamos Ilamar metalingüístico, metajurídico o como sea, pero que en el fondo es un postulado, axioma dirían los matemáticos, del que hacemos depender la justicia, la dignidad u otros valores. Son los axiomas de la ética.

Observamos así que la justicia, la compasión y la humanidad han ido juntas en la historia y que la superación de justicia estricta se ha realizado cuando las otras dos aparecen. Este es uno de los grandes logros que hacen elevarse al género humano. La compasión y la identificación con el sufrimiento son valores que

20. KELSEN, H., ¿Qué es justicia?, Ariel, Barcelona, 1991, p. 36. 
nos acercan a esa aspiración de humanidad compartida. Y esto porque nos mete de lleno en la paradójica naturaleza humana: Schopenhauer, Habermas, Rorty... han visto en la compasión un fundamento de la ética más intenso que el del imperativo kantiano. En el caso de Marcuse, según confesó a Habermas, "¿ves? - dijo a Habermas- ahora sé en qué se fundan nuestros juicios valorativos más elementales. En la compasión, en nuestro sentimiento por el dolor de los otros ${ }^{\prime 21}$.

Es interesante ver aquí la similitud entre la fundamentación ética que Marina pretende y las de otro tipo de éticas como la de la Ética de la Liberación o la de Marx. Así mismo, aparecen los sentimientos de nuevo como los que nos hacen ver lo interesante ${ }^{22}$. Para Horckheimer, por ejemplo, la moral es una disposición psíquica que se condensa en el sentimiento moral; en ese sentimiento que -por decirlo de nuevo con Kant- no apuesta por la ley natural de la apropiación privada o de la propiedad, y que -por decirlo frente a Kant- no se estremece antes del deber, "no es el bastón del caporal -precisará Horckheimer- es el final de la Novena Sinfonía el que expresa el sentimiento moral... Como vemos, Horckheimer se desvía de Kant, al considerar que hay un sentimiento más sublime y más humano que el cumplimiento del deber. Habría que señalar la piedad, la compasión y la solidaridad con lo que cabe preguntarse con Adela Cortina si no es en definitiva la compasión lo que ha puesto en marcha el afán transformador de esta modernidad, que empieza por desconfiar de la idea de progreso. ¿No es la piedad por una humanidad desgraciada la que hace de la crítica y la esperanza en la emancipación una obligación moral?"23.

\section{La teoría de los ganchos trascendentales}

El fundamento práctico con el que Marina pretende afianzar la ética no está completado con la constatación histórica; es necesario también una forma razonada, sistemática, filosófica diríamos, de hacerlo y ésta es la teoría de los ganchos trascendentales a la que ya hemos aludido con anterioridad y que ahora pretendemos sistematizar. Dentro de ella aparecerá la idea de que la dignidad humana es el gancho de nuestra felicidad política que conforma nuestra felicidad personal, que es el objetivo de la invención ética.

Hasta ahora ninguno de los ganchos ha sido aceptado universalmente y por eso, han fracasado: Dios, la Naturaleza, la Esencia humana, el Tao, la Razón universal, la Razón individual, los Valores Superiores... Los ateos rechazan a

21. HABERMAS, Perfiles filosófico-políticos, Taurus, Madrid, 1984, p. 263.

22. Marina ha estudiado esta vinculación entre los sentimientos y la inteligencia en su obra El laberinto sentimental, Barcelona, Anagrama, 1996. En él, el autor estudia la vida emocional como origen de la ética y muestra cómo la educación de la inteligencia afectiva desemboca en una educación ética.

23. CORTINA, Adela, La escuela de Fráncfort, Editorial Síntesis, Madrid, 2008, pp. 136-137. 
Dios, que por otra parte, presenta múltiples caras según las diferentes religiones; los otros ganchos han sido también rechazados en el fondo porque pasan del ser al deber ser, lo que nos remite siempre a las creencias de una sociedad concreta, entre las cuales está la creencia en un nuevo gancho trascendental.

"El primer principio de nuestra teoría diría así: si necesitamos ineludiblemente colgar algo, la inteligencia se esforzará en encontrar o crear un asidero.

Segundo principio: la primera demostración de que algo puede ser un asidero es que sea capaz de soportar lo que necesitamos que soporte.

Tercer principio: Como prueba secundaria de garantía habrá que demostrar que cumple esa función mejor que sus competidores.

Cuarto principio: Todo gancho trascendental es una creación ad hoc. Para afirmar de él algo que vaya más allá de su funcionalidad, por ejemplo su existencia real, debemos hacer otra demostración aparte"124.

Vamos simplemente a mencionar ahora algunas teorías éticas que guardan cierta analogía con estas tesis:

Kant es el más firme antecedente de Marina en la fundamentación ética porque puso el deber como gancho trascendental y a Dios como garante del mismo para evitar que nuestra conducta moral no fuera absurda: "dos cosas /lenan mi ánimo de admiración y respeto, el cielo estrellado sobre mí y la ley moral dentro de mi".

Hobbes y los contractualistas situaron el fundamento social y por tanto también el ético en el contrato. Este punto es el que le interesa a Marina porque tal contrato seguramente nunca existió como ellos afirman, pero cree que debe existir como condición previa para la construcción del edificio ético.

La cuestión está, pues, efectivamente en admitir un gancho trascendental, pero sabiendo que éste será siempre una construcción de la inteligencia, sin darle ninguna categoría ontológica. El asidero que Marina propone es el de la dignidad humana. Es necesario ahora aclarar en qué consiste: para empezar hay que decir que la dignidad es un valor absoluto por definición, no se pierde nunca ni depende de nada, es la percha de la que colgaremos los derechos y por ende los deberes. La dignidad radica en el mismo dinamismo creador de la inteligencia que construye su propia naturaleza y que, ya lo hemos dicho sobre-vive, vive por encima de sus realidades: "vamos a constituirnos, a afirmarnos, a construirnos, a reconocernos como especie con derechos. Es decir a inventarnos una nueva naturaleza, una segunda naturaleza que pueda fundar un derecho natural sui generis, natural y extra natural al tiempo. De una segunda naturaleza. Y vamos a llamar a esa capacidad de afirmarnos como seres valiosos dignidad"25.

24. LLPD 255.

25. LLPD 263. 
Como vemos, somos dignos porque así lo decidimos. Esta afirmación tiene un antecedente claro en Kant. Este gancho trascendental es, por tanto, una afirmación constituyente: dignidad es poseer derechos y reconocérselos a los demás. No hay pues lugar según esta teoría a los recelos de los positivistas jurídicos que ven cómo con esta idea de la dignidad se cuela también el derecho natural. No es que el ser humano tenga por naturaleza valor absoluto, dignidad, sino que necesitamos tenerlo si queremos construir una Ciudad Feliz sobre unos cimientos firmes. No es necesario acudir a un valor absoluto, que ya sabemos el resultado que nos ha dado, no hacen falta soluciones teológicas "el concepto de dignidad ha emergido como un manantial caudaloso que parece brotar de la nada. Pero es el resultado de minúsculas corrientes capilares, que empapan silenciosamente la tierra, la fertilizan, confluyen, para al fin aflorar como manantial. Todos bebemos de lluvias muy lejanas"26.

Este principio: el hombre es un ser dotado de dignidad individual es el principio básico de la constitución universal que Marina pretende construir. Es un axioma constituyente. Epistemológicamente hablando, la invención ética necesita axiomas, igual que las teorías científicas. Ganchos de los que cuelgan todas las demás afirmaciones ¿no hace la matemática y la ciencia en general eso? ¿por qué no la ética? La labor de la ética es descubrir o inventar los mejores axiomas que mejor funcionen para construir la Ciudad Feliz.

Una objeción se podría poner a este sistema trascendental de la dignidad y es que no se ocupa de los deberes. Marina arguye que el hecho moral fundamental y absoluto es un derecho, no un deber. Un deber es un vínculo que exige y la exigencia procede de una orden, de un compromiso o de un proyecto. Los deberes de sumisión, los del derecho positivo, los de contrato y por supuesto los de proyecto no provienen de una autoridad externa sino de un legislador que en este caso es el propio contratante que tiene capacidad para comprometerse. Los derechos son así un colosal proyecto que nos impone serios deberes; hablar de los primeros es fundamentar los segundos.

Los derechos han sido conquistas históricas, nunca gratuitas y que no conviene olvidar. Ahora y aquí nos parecen naturales pero... ¿qué ocurriría si no pudiéramos disfrutar de ellos? Herodoto cuenta que, cuando moría el rey de los persas, quedaban derogadas las leyes durante cinco días, de esta forma el caos y la anarquía hacían ver a los súbditos la necesidad de reponer las normas y la justicia con un nuevo rey. Los matemáticos utilizan la reducción al absurdo para demostrar que si se niega una proposición concreta caemos en contradicción. En el intento de justificar esta lucha por la dignidad y de fundamentar la ética en ella, podemos referirnos también a los intentos históricos de negarla y a sus resultados. Las formas deseables de vivir acaban sobreviviendo en la historia;

26. LLPD 265. 
son los argumentos ad horrorem: "analizando la historia como si fuera un palpitante campo de pruebas, nos parece comprobar que cuando la persona se convierte en un medio y no en un fin, cuando se la instrumentaliza para preservar la cultura, o el grupo o el Estado o el desarrollo, las violaciones de derechos humanos se justifican y el dolor de las personas no es tenido en cuenta. El fin acaba justificando los medios" ${ }^{\prime 27}$.

Y es que cuando la cultura se pone por encima del individuo, la aprobación social o la defensa de la tradición le pueden aniquilar. Todas las reivindicaciones occidentales, la lucha contra la esclavitud o las discriminaciones, han ido en contra de la cultura. Además, la apelación a la tradición cultural se utiliza para legitimar dictaduras. Se apela al respeto y luego a la sumisión. La mujer ha sido probablemente la gran perdedora en esto y lo sigue siendo en muchas partes del mundo. Las culturas deben protegerse pero no a cualquier precio, no convirtiendo a los individuos en víctimas propiciatorias.

Parecidos resultados observamos, según Marina, cuando el Estado se sitúa por encima del individuo. Recientes ejemplos tenemos en el siglo pasado para demostrarlo. No hará falta más que nombrarlos: desde el estalinismo al nazismo. Pero entonces ¿está el bien común por encima del individuo? "nosotros seguimos manteniendo que el bien de la Ciudad feliz consiste en proteger los derechos de los individuos... pero creemos que el derecho introduce a las personas en una red de reciprocidades e intenta ampliar las posibilidades de cada sujeto"2.

Pero, a pesar de todo lo dicho, el mayor horror está en algo que nos estamos empeñando en mantener: la pobreza, la miseria y la guerra. Tres cosas para las que parece que el mundo no tiene solución. Seguramente este mundo no, por eso nos hace falta un estado utópico que bien podría empezar por la Constitución Universal.

El tratamiento ético de la pobreza en el mundo merecería un tratamiento aparte porque además, según el planteamiento que estamos examinando, es una "conditio sine qua non" para lograr el orbe ético. Disponemos de la capacidad necesaria para solucionar el problema, ¿por qué no lo hacemos? Todas las soluciones pasan seguramente por el altruismo de los ciudadanos y los Estados de los países ricos. "Afrontemos el hecho con todas sus consecuencias...si eso provoca que sea extremadamente arduo vivir una vida moralmente decente, bueno, así son las cosas. Si no lo hacemos, entonces debemos saber al menos, que no estamos viviendo moralmente y decentemente, no porque sea bueno revolcarse en la culpa sino porque saber hacia dónde ir es el primer paso para tomar esa dirección"29.

27. LLPD 274.

28. LLPD 290.

29. SINGER, P., Una vida ética. Escritos, Taurus, Madrid, 2002, p. 155. 


\section{Historias de la historia: el progreso moral}

Vamos a examinar ahora un grupo de historias que han conseguido que nos alcemos sobre nuestros principios ancestrales y busquemos una nueva definición del ser humano y un nuevo modo de ser humano. En el fondo, la tesis principal de La lucha por la dignidad es que existe un progreso moral en la humanidad. Lo cual hace imprescindible precisar los valores, que al verse realizados, han mejorado la sociedad que los posibilitó. En diferentes foros ha estado exponiendo Marina los tres criterios que sirven para justificar que una situación, una institución o un modo de vida constituyen un progreso. Por ejemplo en un artículo aparecido en el periódico El Mundo el 29-12-2000, así como en el libro que estamos ahora analizando, dice que una situación histórica y social es buena moralmente:

"1. Cuando satisface más plenamente que otras las aspiraciones legítimas de todos los seres humanos; por ejemplo su deseo de autonomía, seguridad o bienestar.

2. Cuando ningún ciudadano que haya experimentado esa situación y esté libre de miedo o de superstición desearía perderla.

3. Cuando su negación o pérdida conduce al terror. La negación de cualquier garantía procesal en los países bajo dictadura es un buen ejemplo/30.

La historia reciente confirmaría la ley del progreso que hemos anunciado. Por ejemplo, a principios de siglo XX había sólo una decena de naciones cuyo régimen era el democrático. Ahora hay muchas más, aunque en muchas de ellas la democracia sea solamente una etiqueta política, el hecho de que quieran ser reconocidas como tales significa para Marina un progreso. La esclavitud como tal está abolida en todos los países, aunque hayan aparecido nuevas formas de explotación; y es que, ya lo hemos dicho, "la historia de los derechos del hombre es un signo del progreso moral de la humanidad".

Progreso es también el paso de un régimen de status, donde los derechos se tienen por la situación social como el nacimiento, la clase o la raza a un régimen de igualdad donde los derechos se obtienen por ser persona. Como es un progreso el paso de la magia a la ciencia, de la creencia coaccionada a la libertad de conciencia. Progreso es, en fin, el derecho a la educación o a la seguridad jurídica. Pero lo cierto es que estos progresos no son absolutos; la esclavitud sigue existiendo encubierta bajo otras formas, la libertad de conciencia conculcada y la desigualdad entre el primer mundo y los demás es cada vez más manifiesta. Para Marina el avance de la ética es parecido al de la navegación a vela: avanzamos en zigzag y esta técnica produce con frecuencia una impresión confusa:

30. MARINA, J. A., El Mundo, 29-12-2002. 
"cuando se está en un extremo de la línea, antes de invertir la marcha se está muy lejos del rumbo, y además en la mala dirección, de modo que si el timonel no diera el golpe de timón, lo perdería irremediablemente... tengo la convicción de que antes o después la humanidad vuelve al rumbo debido, pero si se retrasa, ¡cuánta tragedia inútil, cuánto dolor sentido, cuánta desdicha injustificable!"³1.

La metáfora de la navegación a vela es buena, pero hemos de tener en cuenta que en la historia no contamos, al menos no siempre, con ese timonel experto; lo que tenemos es la inteligencia compartida, un cambio generalizado de creencias, movimientos sociales lúcidos que trabajen por la felicidad social, por el reconocimiento de los derechos personales, no colectivos, porque es la única manera que tenemos para que, según nos enseña la historia, el individuo no sea sacrificado en favor de la colectividad. Siempre que el Estado se coloca en una situación de superioridad, el individuo pierde importancia. Regímenes de muy diferente signo político como el de Mussolini o el de Stalin así nos lo han mostrado.

El progreso moral aparece, pues, como el marco de fundamentación de la ética. La historia de la humanidad debe ser contada como un intento de librarnos de la violencia y de la injusticia y como una lucha continua por la dignidad. Pero como lo conseguido se nos puede escapar fácilmente, nuestro progreso está siempre en precario. Los ganchos trascendentales son las soluciones descubiertas por la humanidad en su esfuerzo por resolver los problemas de la convivencia. La inteligencia humana es capaz de anticipar y desear las cosas que no conoce con precisión y que, sobre todo, no conoce cómo van a terminar, pero se anticipa y lucha por ello: por la igualdad, por la justicia o por la dignidad. Tenemos, por ello, una deuda de gratitud pendiente con los que creyeron casi en lo imposible y lucharon por conseguirlo. Creyeron en la utopía y prepararon el camino para que la humanidad viviera mejor.

El progreso moral continúa en un gran proyecto: la elaboración de una Constitución Ética Universal que suponga para la especie humana lo mismo que las constituciones nacionales suponen para cada Estado. Esta constitución estaría basada en el reconocimiento de un valor intrínseco de los seres humanos y en la afirmación de la dignidad como reconocimiento y posesión de derechos.

La inteligencia tiene una misión crítica y también solucionadora que debe ofrecer vías para no anular el problema de cómo vivir mejor nuestra vida, sino para solucionarlo. La cultura en general, la ciencia, el arte y sobre todo la ética, resuelven necesidades y problemas. No podemos sentarnos a llorar, a la ética se viene ya llorado. Hay que intentar hacer algo por cambiar lo que está mal. El ser humano es un híbrido de biología y cultura, el progreso moral es como el evolucionismo para la biología. Pero el evolucionismo ético es incomparable-

31. LLPD 50. 
mente más rápido y más manipulable porque el protagonista es la voluntad del individuo y no las circunstancias ambientales. No son precisamente las emociones lo que nos distingue de los animales, sino la capacidad de encauzarlas y domesticarlas.

La ética tiene que buscar el fundamento donde asentarse primero en la capacidad humana para crearla y luego someter su creación a los métodos de evaluación científica o sea a la verificación de sus hipótesis y a las consecuencias de las mismas. Nada mejor que un recorrido por la historia para mostrar lo que ha engrandecido el orbe de la dignidad o lo que nos ha enviado otra vez a la selva. La ética es un gran edificio que vamos construyendo poco a poco, y cada piso se fundamenta en el anterior, por eso conviene ir asegurando los cimientos sobre los que construimos.

\subsection{La invención de las normas}

La invención de la moral como herramienta suprema de la inteligencia se ha visto en la historia de la filosofía desde diferentes perspectivas. Desde luego la visión de Marina no es la de Nietzsche por ejemplo, para quien la moral es una conquista de los débiles: "nosotros no creemos que nuestra idea de justicia haya sido el triunfo del inferior sobre el superior, sino de la inteligencia sobre la fuerza. Una bella victoria"32.

En los primeros tiempos encontramos a la moral unida a la religión y al derecho. Algunas culturas los mantienen hoy día unidos. Pero la inteligencia analiza e intenta separar para evitar la confusión. Todos los sistemas normativos pretenden fomentar los valores que una sociedad considera fundamentales y están al servicio de la justicia. La parte de las normas que se impone por coerción la llamamos derecho. Y el derecho es el más claro ejemplo de progreso moral porque, en principio, lo que intenta es resolver conflictos y hacerlo de manera racional. Pero el derecho tiene también un largo camino. Veámoslo someramente en tres asuntos que marcan su evolución histórica: la reglamentación de la venganza, la aparición de los jueces y la figura del legislador.

La venganza fue quizá de los primeros métodos utilizados para la reconciliación y la estabilidad del grupo pero las sociedades han tenido que protegerse de este método tan primitivo: desde refugiarse en lugar seguro a pedir asilo. La aparición de un tercero en el conflicto o de un mediador ha sido una inteligente medida, por eso la aparición de un sistema judicial es una de las actuaciones de la razón práctica para conseguir poner a salvo ciertos valores, así llegamos a las sociedades modernas donde el Estado monopoliza esa "venganza".

32. LLPD 55. 
Vemos así que la relación entre moral y derecho es muy estrecha. Los bienes o los valores nos mueven a la acción para alcanzarlos, conservarlos o evitar su ausencia. Pero ¿cuándo se considera un conflicto resuelto? ¿Cuáles son las soluciones mejores? Desde luego, la fuerza es una solución, pero nadie dudará de que no es la mejor. Durante milenios y aún hoy día, disfrazada de mil formas, la empleamos. El recurso a la fuerza no puede ser un valor fundamental para la convivencia de los seres humanos, por eso no es bueno, porque no es el modo legítimo de resolver conflictos, es decir, no es un modo que pone a salvo los valores fundamentales de una sociedad, como por ejemplo la cohesión del grupo. Apelar a la fuerza es igualar lo mejor con lo más fuerte, es no salir de la naturaleza o de la selva.

La apelación a un tercero, a un juez, parece un gran progreso y tradicionalmente ha habido dos poderes que se han apropiado de la facultad de juzgar: la religión y los soberanos. En el Antiguo Régimen Jurídico, la ley estaba por debajo del legislador y los derechos por debajo de la ley; pero hubo una auténtica revolución con el Nuevo Régimen Jurídico que separó el derecho de la religión o del legislador. Se distingue bien lo que pertenece a la esfera privada y lo que es de la esfera pública. Este camino es el llevado a cabo en occidente y es el camino correcto porque es el único que admite la crítica, la fundamentación y el debate ${ }^{33}$.

El mundo musulmán nos ofrece en esto un ejemplo porque no ha experimentado ese tránsito a la modernidad y esto es un grave obstáculo en nuestro pretendido progreso moral. El mundo griego nos enseñó sin embargo el otro camino, el de separar a los legisladores del poder político: las leyes de Solón en el siglo $\mathrm{V}$ antes de Cristo no eran "thesmoi", algo impuesto desde lo alto, sino "nomoi", costumbres aceptadas por el pueblo. Ésta es una línea de progreso. El legislador ya no se rige por el soplo divino sino por la razón y la capacidad de convencer a los ciudadanos. La democracia como forma de legislar está llamando a la puerta.

El progreso moral empieza así con el abandono de la fuerza y la venganza, pero es sólo la primera piedra del edificio moral y también de su fundamentación. Las plantas de este edificio son la lucha por la libertad, por la igualdad, por la seguridad y por la fraternidad y a ellas vamos a dedicarnos ahora, analizando una serie de aspiraciones que los humanos han conseguido a lo largo de muchos años de historia. De manera que realizaremos un pequeño recorrido histórico

33. Marina ha estudiado este asunto en sus libros Dictamen sobre Dios, Anagrama, BarceIona, 2001 y en Por qué soy cristiano, Barcelona, Anagrama, 2005. En el primero aboga por las religiones de la segunda generación que son las religiones sometidas a un criterio ético universal y que admiten la distinción entre verdades privadas y verdades públicas. En el segundo, mantiene que las verdades religiosas deben ceder el paso a las verdades universales para que haya una especie de reconciliación con la ética. 
por las aspiraciones humanas más nobles que han hecho que sobre ellas construyamos nuestra civilización y seamos capaces de aspirar a un mundo mejor.

\subsection{La lucha contra la esclavitud}

Las palabras siempre vienen en nuestra historia antes que los hechos, pero esto es ya un primer paso: aunque la esclavitud siguió siendo legal hasta 1980 en el último país que la abolió, Mauritania, en 1776 en la Declaración de Virginia se declara que todos los hombres son iguales. Pero también es verdad, que hasta el siglo XIX era legal en España.

Nos podemos preguntar ahora: ¿cómo ha podido tolerarse durante tanto tiempo este negocio? Pues porque intereses y mitos de la legitimación lo han hecho posible. Veremos aparecer estos mitos y estos intereses a lo largo de nuestros hitos históricos, nuestra misión será descubrirlos para descubrir también las razones sobre las que se asentaban los comportamientos sociales que suponían una rémora para el progreso moral. De momento, valga como un ejemplo para el mito de legitimación de la esclavitud el que propone Aristóteles para quien los esclavos carecían de razón y por tanto no eran personas.

¿Por qué valoramos tanto la libertad? Porque es lo que nos permite desarroIlar un proyecto personal de felicidad. Como decía Stuart Mill, todo hombre quiere que le dejen organizar su vida "porque su propio modo de arreglarla es el mejor, no porque lo sea en sí, sino porque es suyo... quédese el lector con esto: la lucha por la libertad fue al comienzo un empeño por huir del dolor y por estar en buenas condiciones para alcanzar la felicidad. Y esto, en último término, es un empeño individual'34.

La primera fase de la lucha contra la esclavitud se sintetiza en el grito de ¡quiero ser libre! Hay que diferenciar la lucha por el propio interés de la lucha por la reivindicación de un derecho, sencillamente porque en esta última pueden colaborar personas que no están directamente implicadas. Y así, vemos que en las luchas abolicionistas hubo personas que no eran esclavos. Las ONG que reclaman atención y derechos para el tercer mundo no pertenecen a él; los teólogos o filósofos de la liberación son en ocasiones gente ajena a ese mundo, etc., etc. Es decir, la característica que nos hace especiales y nos hace progresar es el hecho de que haya siempre alguien que vaya más allá de sus propios intereses y sea capaz de luchar por una situación mejor. De ahí también que la utopía haya sido tan importante para la historia humana.

Otra característica tuvo la lucha contra la esclavitud que es imprescindible en otras luchas reivindicativas: fue plural e internacional; se peleó en varios y muy diferentes frentes: en Europa, sobre todo en Inglaterra y en América en los

34. LLPD 78. 
Estados Unidos. Por otra parte, cualquier lucha reivindicativa cuenta con acciones individuales que merecen pasar a la historia, tal es el caso por ejemplo de los escritores o filósofos de la Ilustración que proporcionaron argumentos contra la esclavitud. Es interesante a este respecto la cita del enciclopedista D'Alambert cuando dice que "son las circunstancias y no la naturaleza de las especies las que han decidido la superioridad de los blancos sobre los negros ${ }^{\prime \prime 35}$. Y es interesante porque aquí aparece lo que Marina llama el gancho trascendental que en esta ocasión sirve para deslegitimar la esclavitud: las circunstancias. Luego lo que parece claro es que las circunstancias se pueden y deben cambiar. En la naturaleza nada hay escrito sobre este asunto y las circunstancias son fruto en muchas ocasiones de la acción humana.

Esta trágica historia de la esclavitud nos indica las claves de por qué la lucha contra ella y su erradicación es un progreso moral que sigue estos pasos: echar en falta, rebelión, legitimación, reconocimiento social, reconocimiento legal; y que en el caso que nos ocupa, discurre por estas fases:

1. Primero los afectados no sólo quieren su libertad sino también su derecho a ser libres.

2. El éxito es también de otras personas que consideran un atentado a la dignidad la ausencia de libertad.

3. Como fundamento legitimador aparece el gancho trascendental de los derechos naturales. Pero es un gancho comodín: en este caso, como en otros muchos, la naturaleza vale tanto para permitir la esclavitud como para prohibirla.

\subsection{La lucha por la democracia}

¿De dónde vienen los derechos individuales? Distintos ganchos trascendentales hemos inventado para responder a esta pregunta.

1. Del poder (positivismo jurídico).

2. De Dios (iusnaturalismo religioso).

3. De la Naturaleza (iusnaturalismo laico).

4. De la voluntad popular (positivismo).

Vamos a exponer ahora la evolución de estas respuestas a aquella pregunta.

Una de las mejores cosas que el ser humano ha construido para asegurar su ámbito privado de libertad es la democracia. La democracia como sistema político fue inventada por los griegos y nació cuando la lucha contra el despotismo

35. LLPD 89. 
llegó a su final. Se trataba de ser libres o esclavos y querían su libertad para decidir el modo de vivir. No es que la democracia descubra las leyes sino que descubre que la ley es igual para todos, y por tanto parece requisito imprescindible que los ciudadanos participen de la elaboración de ella, y ahí es donde aparece el logos, la razón, como la principal herramienta que sustituye a la fuerza para imponer un modo de vivir.

La democracia ateniense no duró mucho y no volverá a aparecer hasta pasados siglos, pero siempre quedó como un ideal a perseguir. En el siglo XX y finales del XIX hay una creciente pujanza de la democracia; este dato demuestra la fuerza de la argumentación práctica a favor de ella como progreso moral. Al examinar de nuevo la historia de la democracia observamos que ha habido en su contra dos obstáculos por lo demás sempiternos: los intereses y los mitos de legitimación. Los intereses son los deseos de poder y de gloria; y en cuanto a los mitos se vuelven a repetir los de la naturaleza (el orden natural debe respetarse o iremos al caos) o Dios como legitimador y origen del poder que lo otorga por gracia a una persona o a una dinastía. Naturaleza y Dios vuelven a ser los ganchos trascendentales sobre los que se hace pender toda autoridad.

Pero esta conquista del poder lleva aparejada la preocupación por ponerle límites; "la libertad individual surgió como consecuencia de la lucha por el poder más que como el fruto deliberado de un plan, escribe Hayek. Para romperla hubo que romper no sólo miedos, sino creencias fuertemente arraigadas. Como siempre. La mayor parte de las culturas en su origen desconfían de la libertad individual/36.

El liberalismo supuso un gran paso en esto, porque el liberalismo es básicamente un sistema que, buscando proteger al individuo, legitima pero pone límites al poder, porque considera que los individuos tienen derechos previos al Estado. Había que limitar el poder del gobernante ¿cómo?, apelando a algún gancho trascendental, y aquí la ley natural o Dios cambió de signo: Dios limitaba con sus preceptos los poderes del soberano porque es el máximo legislador; el rey debía su autoridad a él, que a su vez, no estaba sometido a ninguna. Por otra parte, se recurrió también a otro gancho trascendental: la apelación a una ley más antigua donde los derechos previos limitan el poder del soberano.

La segunda pregunta a contestar sería: ¿Dónde reside el poder? Aparece un nuevo mito con la democracia: en la voluntad popular. Esta fue la respuesta en la llustración: ¡quiero ser ciudadano!, quiero ser "zoon politicon", como decía Aristóteles. Pero si la obediencia a las leyes garantiza libertad, es porque están hechas por los hombres en consentimiento común. Y aquí chocamos con otro problema: puede haber leyes injustas que se hayan aprobado por mayoría; o sea que se mantiene el esquema tradicional, lo que ocurre es que en este caso el

36. LLPD 105. 
soberano legislador no es un soberano sino la nación, y este soberano podría comportarse despóticamente.

Y así, para evitar la tiranía de la mayoría, se restringe el derecho al voto. Es como si estuviéramos siempre en un tira y afloja con nuestros derechos; se los ofrecemos al Estado pero a condición de que nos los cuide. Rousseau ya planteaba el problema: "encontrar una forma de asociación que defienda y proteja con toda la fuerza común a la persona y a los bienes de cada asociado, por lo cual, uniéndose cada uno a todos, no obedezca sin embargo más que a sí mismo y permanezca tan libre como antes. Tal es el problema fundamental cuya solución da el contrato social ${ }^{137}$.

En definitiva, pues, con la democracia los problemas no han hecho más que empezar. Uno más: ¿hasta qué punto es absoluta la soberanía popular? ¿Cómo hacer que una democracia no pueda desembocar por su propia elección en un régimen tiránico?, ¿puede un legislador, aunque sea la voluntad general, legislar para siempre? Tenemos que recurrir a un antiguo gancho trascendental: los derechos individuales son previos al sufragio, al pueblo, y a la sociedad. Son derechos innatos e imprescriptibles. Son anteriores, son la base sobre la que se asientan los demás, son los cimientos del edificio ético de los derechos y éste se nos caerá entero si quitamos las piedras angulares.

Algunos pudieran ver aquí resurgir el iusnaturalismo como teoría del origen de los derechos, al considerar que son innatos, y esto es algo que Marina repite en diversos momentos y en varios de sus libros; ésta es una vieja polémica y además en muchas ocasiones estéril. Hablando de los derechos, no es lo importante de dónde vienen o de dónde brotan, sino quién y cuándo se tienen que reconocer y cómo contribuyen al progreso, en este caso moral; y esto está más cerca, creemos, de una teoría positivista. Positivismo vs. Iusnaturalismo. Ni uno ni otro, sino todo lo contrario. El iusnaturalismo no, porque no podemos fundamentar la ética en la naturaleza, salvo que la entendamos simplemente como el complejo entramado de capacidades que convergen en el ser humano formando la inteligencia. En la naturaleza no hay ética, sólo su posibilidad. Si apelamos a aquella, apelamos también a la ley de la fuerza. El primero, el positivismo, fuerza la salida de la selva con un contrato; de forma que ése sería el fundamento de la ética. Marina cree que tampoco es exacto; por ejemplo, las cosas no son buenas o malas porque así lo decidamos, sino que los son porque contribuyen a la felicidad personal y social, contribuyen al orbe de la dignidad.

Seguramente a Marina le hubiera gustado encontrar un fundamento más técnico de la ética que la mera enunciación de procesos históricos de liberación, pero al final no es posible si situamos la ética donde debe estar: enfrente de ius-

37. ROUSSEAU, J. J., El contrato social, libro I, capítulo 6, Alianza Editorial, Madrid, 1980, p. 22 . 
naturalistas y positivistas. Porque se trata en ella de mostrar que obrar moralmente o éticamente interesa, siguiendo casi el modelo de racionalidad que inaugurara Sócrates, para quien existe una relación analítica entre racionalidad práctica e interés.

Hume incluyó la moral en el ámbito de las ciencias al explicar mediante las operaciones de la naturaleza humana las manifestaciones de los sentimientos que crean el universo de la moralidad. Kant también parte de lo mismo, pero considera que los juicios morales expresan una necesidad cuyo origen no puede estar en la experiencia sensible, sino que ha de ser a priori, limpio de cuanto sea empírico. De forma que la cuestión naturalista es cómo puede la realidad ser racional, mientras que la kantiana es cómo puede la razón pura ser práctica. Marina une las dos, por eso su estudio converge con las ciencias, cuyo objeto es el estudio de la acción humana: psicología, sociología, historia, antropología... De ahí que aparezca soterradamente el concepto de interés o de utilidad como categoría básica.

\subsection{La lucha por la libertad de conciencia}

Se reivindica en esta lucha el derecho a tener y expresar las propias creencias y a comportarse de acuerdo con ellas. Veamos ahora los intereses y los mitos de legitimación con los que se tiene que enfrentar. Cuando nos liberamos del miedo, del dogmatismo y de la ignorancia, reclamamos un ámbito privado y en ese ámbito privado está la libertad de conciencia. Pero como en todo lo que estamos estudiando conseguirla no ha sido gratuito; hemos tenido que desmontar varios "demonios" o mitos o creencias que han funcionado como verdades contrastadas: Erich Fromm estudió en "El miedo a la libertad" el mecanismo social y psicológico que actúa como freno en nuestra conquista de la libertad.

El mito de la coherencia social: el miedo a perder la cohesión del grupo hace que la discrepancia se vea como un peligro. Quizá nos parezca un poco lejana esta creencia pero, si nos fijamos, encontramos señales para pensar que hoy día el mito de la identidad cultural ha sustituido a la cohesión social como gran valor a salvaguardar.

El mito de la cosificación de la verdad. La concepción de la verdad como algo que existe fuera del individuo y éste no tiene otra función más que aceptarla. "Frente a la cosificación de la verdad se alza la verdad como función vital. Lo importante no es sólo el contenido sino el modo como cada sujeto llega a él, se lo apropia y es capaz de justificarlo. Esto exige capacidad crítica y esfuerzo. La búsqueda de la verdad se convierte en un deber ético. Una parte indispensable de la búsqueda de la justicia"38. En parecidos términos se expresa Nietzsche o Schopenhauer cuando hablan de la vida como realidad radical.

38. LLPD 119. 
El mito de la obediencia como perfección: se toma la obediencia como protección contra la incertidumbre. Como es natural, en este mito y también en los anteriores, las religiones han tenido mucho que ver. Pero lo que puede ser válido o quizá imprescindible en un marco religioso es inadmisible en un entorno laico, en el que el individuo ha de salvarse a sí mismo y conquistar su propia libertad. Recordemos a este respecto, por ejemplo, las palabras de B. Russell: "La incertidumbre, frente a las vehementes esperanzas y temores, es dolorosa, pero hay que soportarla si deseamos vivir sin tener que apoyarnos en consoladores cuentos de hadas... Enseñar a vivir sin esta seguridad y, con todo, no sentirse paralizado por la duda, tal vez sea el mayor beneficio que la filosofía puede aún proporcionar a quien la estudia"39.

Erich Fromm en la obra citada más arriba ha estudiado ampliamente todos estos aspectos en los que se ve sumido el ser humano al verse por una parte necesitado del grupo y por otra obligado a realizarse personalmente y perseguir este derecho a la personal búsqueda de la verdad. Ahora bien, "la libertad de conciencia sólo adquiere legitimidad total cuando esa conciencia se compromete a buscar la verdad, a escuchar argumentos ajenos, atender a razones y rendirse ante la evidencia, aunque vaya en su contra"40.

Un nuevo peligro nos amenaza en toda conquista de la libertad: el relativismo, el pensar sin más que todas las opiniones son respetables. Los derechos permiten pero a la vez exigen y en este caso exigen la racionalidad bien entendida, la eliminación del fanatismo y la obstinación. Válganos ahora simplemente otra cita breve: "Cada vez que se dice respeto su opinión, aunque no la comparta, se está diciendo algo parecido a lo que anuncia el espíritu posmoderno: que no hay principios intangibles, ya que el enriquecimiento de la vida humana está en la diversidad. Lo malo es si el opinante es Jack el Destripador. Parece más correcto decir: le respeto a usted, aunque su opinión me parece detestable ${ }^{\prime \prime 41}$.

\subsection{La lucha por la igualdad de la mujer}

La igualdad es también una conquista y en el caso de la lucha por la igualdad de la mujer estamos todavía en pañales, aunque se han dado pasos de gigante en los últimos tiempos. La lucha por la igualdad en general está presente en toda la historia; nos referimos a esa lucha por eliminar aquellas diferencias corregibles y que dificultan o impiden la búsqueda privada de la felicidad porque discriminan, excluyen o prohíben que un grupo o un individuo acceda al disfrute del bien.

39. RUSSELL, B., Historia de la filosofía occidental, Espasa Calpe, Madrid, 1984, pp. 10-11. 40. LLPD 127.

41. MARINA, J. A., Crónicas de ultramodernidad, Anagrama, Barcelona, 2000, p. 55. 
En esta crónica de invención de la humanidad debemos hacer un hueco para esta reivindicación porque en casi todo el mundo la mujer sigue padeciendo las mayores discriminaciones; la pobreza, el analfabetismo y el sometimiento les Ilega especialmente a ellas. Esto sin contar con la situación de las mujeres en muchos países islámicos donde siguen vigentes los mitos legitimadores que mantienen en el aire esta situación: el de que la mujer es peligrosa y el de que la mujer es mentalmente inferior. Estos dos mitos han hecho que a lo largo de la historia a las mujeres haya habido que controlarlas, tutelarlas, limitarlas en su libertad.

Este movimiento reivindicativo tiene apenas dos siglos y podemos asombrarnos si recordamos cómo, por ejemplo, en España hasta el año 1975 la mujer no tenía la patria potestad sobre sus hijos o no podía trabajar, ni abrir cuentas en un banco o tener pasaporte sin licencia del marido. O cómo hoy día muchos grupos de mujeres, sobre todo musulmanas, luchan y se aferran a esta discriminación porque la consideran de identidad cultural. Es más, podemos decir que sólo en las sociedades desarrolladas la mujer ha pasado de ser maltratada o ignorada a ser equiparable al hombre.

Tengamos en cuenta en esta lucha que las mujeres que luchaban por los derechos civiles, admitidos para los varones, luchaban por su dignidad, es decir por el desarrollo de su libertad y de su felicidad, que son las aspiraciones que siempre están presentes en todos los sistemas reivindicativos.

La lucha por la igualdad de la mujer ha llevado a algunas feministas a reclamar el derecho a la diferencia, pero como ya hemos mencionado, reclamar derechos colectivos "plantea a nuestro juicio más inconvenientes que ventajas. El grupo puede anular o desdibujar al individuo. Basar derechos en la diferencia sólo conduce a que cada grupo pueda reclamar los suyos... Fueron las feministas quienes se dieron cuenta de que frente a la diferencia -ser mujer- se podía levantar otra diferencia -ser hombre- y una superdiferencia -ser machista. Comprendieron entonces que lo importante era reivindicar los derechos universales y luchar contra las discriminaciones ${ }^{\prime \prime 42}$.

O sea que la lucha por la no discriminación es más universal, más ética, más progresista que la lucha por la diferencia; porque lo que la postura ética defiende es que no se puede privar a nadie de sus derechos personales por razones ilegítimas. Los derechos los tenemos por pertenecer a la especie humana. Este es el nuevo gancho trascendental del que penden todos los demás, por ejemplo el derecho a la diferencia. Si se poseen derechos por poseer un rasgo que no es universal estamos apelando a la fuerza como gancho trascendental y ya hemos visto que la ley del más fuerte no es precisamente la ley ética por excelencia.

42. LLPD 145. 
Apelamos a los derechos privados para vivir mejor, para vivir fuera de la razón de la fuerza, si es que se le puede llamar razón. Las discriminaciones que son fruto de la fuerza, por tanto, sólo tienen esa razón de ser, debemos eliminarlas (las discriminaciones por razones de sexo, raza...), la discriminación que es fruto de la razón social debemos mantenerla (la discriminación a asesinos por ejemplo).

\subsection{La lucha contra la discriminación racial}

La primera elección del ser humano sobre el modo de vida que quiere vivir es o selva o ética, o fuerza o razón. El tránsito de la biología a la moral es el paso del determinismo a la libertad, el tránsito de la naturaleza a la historia. En La lucha por la dignidad se nos ofrecen dos ejemplos históricos recientes de este tránsito: el llevado a cabo en Sudáfrica por Nelson Mandela y el de Estados Unidos en su lucha contra la segregación racial liderado por Luther King y lleno de humildes y heroicas aportaciones como la de Rosa Park, la mujer negra que se negó a dejar su asiento en un autobús a un hombre blanco.

Son ejemplos muy conocidos y estudiados desde diferentes puntos de vista, por eso no nos detenemos en ellos. Pero en este sentido, recordaremos el estudio que hace el antropólogo Stephen Gould en su libro La falsa medida del hombre donde intenta demostrar tanto la debilidad científica como el condicionamiento político de las argumentaciones deterministas basadas en la biología. Cuenta Gould cómo el mito platónico de que los seres humanos estamos hechos de oro, de plata, de bronce o de hierro se ha visto reproducido de diferentes formas a lo largo de la historia para justificar o legitimar el que como decía Platón unos estén hechos para mandar, para ayudar o para ser artesanos: "Las razones para establecer una jerarquía entre los grupos basándose en sus valores innatos, han ido variando... podemos llamar determinismo biológico a la argumentación general que para ello se aduce. Consiste en afirmar que tanto las normas de conducta compartidas como las diferencias sociales y económicas que existen entre grupos, básicamente diferencias de sexo, raza y de clase, derivan de ciertas distinciones heredadas innatas y que, en este sentido, la sociedad constituye un fiel reflejo de la biología ${ }^{1 / 43}$.

\subsection{La lucha contra la arbitrariedad jurídica}

Conseguir una defensa justa frente al poderoso ha sido también una constante histórica y por ende una lucha que ha contribuido al progreso moral que estamos constatando. Uno de los poderes que más ha sido codiciado por los

43. GOULD, S., La falsa medida del hombre. Ediciones Orbis, Barcelona, 1984, p. 2. 
poderosos es el poder judicial. Por eso, también es una conquista la separación de los tres poderes que la Ilustración preconizó.

El conocimiento de la ley, la presunción de inocencia, la responsabilidad de un acto, la necesidad de testigos, la confesión sin torturas son mecanismos impuestos por la razón para salvaguardar el derecho a ser juzgado justamente. Son luchas por dignificar al ser humano y en este capítulo, como en los otros, el camino está lleno de seres desconocidos y anónimos que fueron valientes y esforzados por crear algo que antes no existía. Hemos mencionado más arriba el progreso que supone también para la humanidad el establecer un tercero como mediador o juez admitiendo así que el Estado sea el depositario de la "venganza" primitiva; de tal manera, que los juicios americanos empiezan: "El Estado contra el ciudadano $X$ " dando muestra de quién es el depositario de la justicia y quien debe administrarla.

\subsection{La reivindicación de la fraternidad}

¿Cuáles han de ser las relaciones entre los miembros de la comunidad? La historia nos dice que la mejor forma de conseguir la justicia es afirmando los derechos individuales que, como hemos dicho, serían previos a la ley, o por decirlo de otra manera, innatos. Occidente ha conseguido una felicidad política, que se sustenta en una comodidad individualista, un bienestar sin esfuerzo donde la idea de fraternidad empieza a sonar a anacronismo o a beatería: "las reivindicaciones son una experiencia reflexiva de la sociedad. Nos han enseñado que el mejor modo de librarse de la arbitrariedad, de la discriminación, de la tiranía, es afirmar que el ser humano nace con derechos. Es decir, que posee derechos subjetivos sin que una ley previa se los haya concedido" ${ }^{\prime 4}$.

Pero a nosotros nos interesa explicar el significado de ese tener derechos. ¿Por qué tenemos derechos? Los ganchos trascendentales que han servido para hacer depender o justificar o fundamentar los derechos se han mencionado con anterioridad: Dios, la Naturaleza, la Razón; pero ya hemos visto que todos ellos han sido utilizados para justificar las reivindicaciones o para deslegitimarlas, y cuando algo sirve para una cosa y para su contraria es que no sirve. Hay que buscar el fundamento en otro sitio o quizá resignarse a no encontrarlo nunca de forma definitiva.

Para empezar hay que decir que tener derechos es poder, pero poder tanto significa tener capacidad como ausencia de prohibición. El primer significado es con relación a la ética y al derecho, el más completo y el más importante. En la lucha por la dignidad se define así: "Derecho es un poder eficaz y simbólico que permite a un sujeto realizar pretensiones reconocidas por la comunidad".

44. LLPD 193. 
El poder así concebido aumenta nuestra actuación, pero es un aumento que se sustenta en algo inventado, simbólico; en algo que es como "de mentira", se fundamenta en algo que no existe, pero que... funciona. Como el dinero, el derecho es un bien simbólico que busca otra fuerza que no sea la del propio sujeto, sino el reconocimiento activo de toda la comunidad; es por eso, una realidad mancomunada. El lenguaje, las costumbres, las tradiciones, son otros ejemplos de realidades simbólicas

La inteligencia humana ha inventado esta solución-concepción de la ética y del derecho. Los derechos innatos no son propiedades reales, sino posibilidades reales del ser humano, o sea, se pueden tener o no. La historia, la ética decidirán qué es mejor. La sociedad en la que vive el individuo es como un gran edificio, buscar el fundamento adecuado es asegurar el edificio; a partir del modo de vida que tenemos como objetivo edificable, inventamos la estructura que nos permitirá edificar. Pues bien, los derechos individuales, previos a la ley, son esa estructura.

Esta concepción de la fundamentación de la ética exige una especie de voluntarismo, si es que no queremos privar de los derechos a los débiles o a las minorías que por diversas razones aún no los pueden tener. La voluntad se une, por tanto, aquí a la inteligencia (si es que no ha estado unida desde siempre) a servir también de cimiento de la ética. Tenemos derechos porque queremos tenerlos, porque nuestra inteligencia computacional y nuestra inteligencia ejecutiva los ven necesarios para la realización personal y colectiva y entonces nos proclamamos y nos erigimos en sujetos poseedores de derechos. Tendemos la mano para ver de dónde colgamos nuestras pretensiones y nos encontramos de nuevo como el barón de Münchausen que se salvó de morir en el pantano tirándose de los pelos hacia arriba. No podemos agarrarnos a ningún gancho, trascendental o salvador, hemos de construirlo nosotros. La humanidad se ha de salvar a sí misma con la voluntad, y la humanidad será quien imponga los límites de la comunidad. Primero porque hemos fundado en la persona la posesión de derechos y segundo porque la historia nos remite a la peligrosidad de las discriminaciones y a que es mejor afirmar la universalidad.

Y aquí es donde entra la noción de fraternidad. La reivindicación de la fraternidad es el movimiento más actual y necesario si queremos Ilegar a la noción de humanidad. El nuevo gancho trascendental no es ya la naturaleza sino el deber de comportarnos fraternalmente como se dice en la Declaración de los Derechos Humanos: "todos los seres humanos nacen libre e iguales en derechos y dignidad, y dotados como están de razón y conciencia deben comportarse fraternalmente los unos con los otros". Como podemos ver, la naturaleza ha desaparecido, y con ella creemos que también el derecho natural; además, se ha pasado de un indicativo en el que se afirma la fraternidad por razones religiosas o naturales a un imperativo de orden moral. El deber de comportarse de una manera concreta. 
La idea clave es por eso la de Humanidad porque "el obsesivo afán por buscar la identidad personal en la cultura o en la pertenencia a un grupo, puede desembocar en conductas peligrosas... La única solución a la que este libro quiere contribuir es a identificarnos por la historia única de la que dependemos todos: la historia de la humanización... la biología nos proporciona la especie zoológica. No es suficiente. Lo que necesitamos construir es La Humanidad como categoría ética ${ }^{\prime \prime 4}$.

Se trata, pues, de inventar una segunda naturaleza que rectifique y complete a la primera. Esta es la gran tarea humana y también de la ética. Ver en ello una nueva forma de iusnaturalismo nos parece erróneo, de forma que, creemos, Marina rechazaría la vieja polémica entre positivistas y iusnaturalistas. Como dice un proverbio oriental, "gato blanco o negro... lo importante es que cace ratones". Que el fundamento de la ética sea positivo o sea natural importa poco, lo que hay que ver es que sea un buen cimiento sobre el que edificar nuestro edificio.

Si queremos, pues, recapitular el proceso de fundamentación de la ética diremos que a la pregunta de cuál es el fundamento de la ética, habrá que responder: pues... ninguno. No existe. Todo depende de lo que queramos hacer. Inteligencia y voluntad unidas en un bucle ascendente. Por eso también nuestra esencia es nuestro futuro, lo que seamos capaces de hacer. A quien pueda extrañar esta solución de Marina que recuerde, por ejemplo la respuesta que daría Ortega o Zubiri a la pregunta por la naturaleza humana: no tiene; o a la que daría Sartre por la de la esencia humana: porvenir, existencia.

Compasión e indignación trabajan en nuestra inteligencia para construir este pretendido orbe ético porque nos exige tomar en serio el sufrimiento y la humillación. Ahí hace precisamente radicar su fundamento la ética de la liberación en "la mirada del otro": "el punto de partida de la ética de la liberación es la evidencia vivencial ética de la interpelación del pobre... y de esta experiencia de la exterioridad (Lévinas) de los derechos del otro resulta una evidencia para la toma de partido necesaria y ética ${ }^{\prime \prime 46}$. En este aspecto, la ética de la liberación y la ética de Marina se dan la mano, puesto que ambas consideran que es imposible fundamentar la ética sin el recurso a la intersubjetividad como condición humana incondicionada. Se entiende así la vida humana como una relación intersubjetiva en el que el otro se me impone incondicionalmente como algo que debe ser afirmado. Mi libertad, mi autonomía, mis derechos, diría Marina, se encuentran cara a cara con los derechos, la autonomía y la libertad de los otros cuya vida aparece así como digna de ser afirmada y como condición para afirmar también la mía. Por eso, cuando desaparece la convicción de que fren-

45. LLPD 203.

46. DUSSEL y APEL, Ética del discurso y Ética de la Liberación, Editorial Trotta, Madrid, 2004, p. 251. 
te a mí hay otro que no puedo ignorar, por decirlo de otra manera, cuando desaparece la compasión, parafraseando al personaje de los hermanos Karamazov, "todo está permitido": "Nosotros estamos empeñados en mantenernos en el terreno dramático de las ideas prácticas. La claudicación histórica de la compasión cuando desaparece la creencia en el valor intrínseco de la persona, es un ejemplo científicamente válido ${ }^{\prime \prime 47}$.

La cuestión, pues, es que hay un argumento real que es el que nos da la historia de genocidios, miserias y pobrezas; por eso quizá haya que ignorar a los "estilistas del pensamiento" que desprecian cualquier argumento práctico porque ni parte de conceptos ni concluye en conceptos, se mueven en el cielo platónico de las ideas y, como la paloma de Kant, creen que allí se podrá volar mejor sin resistencia al aire.

Necesitamos una constitución universal con sus tribunales y códigos universales como ya preconizaba B Russell, y de ella hablaremos luego. En esta reivindicación de la fraternidad unos organismos se llevan la palma: las ONG. El problema es que estos movimientos se mueven en un nivel de invención ética y necesitamos el nivel de la justificación: por eso hay que ordenar y criticar la experiencia histórica para ver si su argumento nos sirve.

\subsection{Dos momentos estelares}

En este recorrido por la historia de las reivindicaciones éticas, hay dos momentos estelares en los que la ética y el derecho han ido perfectamente integrados. No olvidemos que la tesis central de los autores en La lucha por la dignidad es: si queremos construir un edificio de veinte plantas necesitamos que los cimientos sean bastante fuertes para que las aguanten, si queremos tener felicidad pública, paz, seguridad y libertad hemos de tener derechos previos a la ley. La Declaraciones de los Derechos del Hombre y del Ciudadano en Francia en 1789 y la Declaración Universal de los Derechos Humanos de 1948 consagraron este invento moral de poner los derechos antes que la ley ${ }^{48}$.

La Declaración de 1789 utiliza un nuevo gancho trascendental de donde colgar los derechos: se trata de la voluntad de la nación. Dios y la Naturaleza han desaparecido. La Declaración apelaba a unos derechos innatos y sagrados sin ocuparse de fundamentarlos. Aspiraba a instaurar un nuevo modelo de sociabilidad que admitiera un derecho natural pero sin ligarlo a nada ni a nadie, un derecho para los individuos, sobre el que construir una nueva humanidad.

47. LLPD 205.

48. J. A. Marina ha realizado un exhaustivo análisis de la Declaración francesa en su libro Los Sueños de la Razón, ensayo de la experiencia política, Anagrama, Barcelona, 2003, donde de forma novelada nos mete de lleno en los días más fecundos de la Revolución Francesa en los que se redacta la histórica Declaración. 
¿De dónde se sacaron esos derechos? No les importó demasiado; lo realmente importante era que sobre ellos, sobre esa voluntad, se podían colgar las leyes.

La Declaración de los Derechos Humanos tiene naturalmente otro contexto histórico que viene marcado por su carácter internacional, con lo que pretendía limitar el poder de los Estados de tal manera que los derechos humanos y las libertades fundamentales, algunas de las cuales hemos estudiado en la historia de su reivindicación, son una cuestión internacional donde los derechos aparecen de nuevo como anteriores al legislador, son supranacionales y suprasoberanos.

En 1948 el ambiente era favorable a los derechos humanos como garantías para la paz y aún así, la forma como éstos se entendían fue motivo de encendidas discusiones. Por ejemplo, los países del bloque socialista consideraban que no se podía limitar la autoridad del Estado y que la soberanía nacional estaba por encima de los derechos humanos. Además, insistían en que lo prioritario era instaurar los derechos económicos y sociales. El bloque occidental, sin embargo, tuvo que admitir a regañadientes estos últimos derechos mencionados porque de lo contrario no se admitirían los derechos de carácter político.

Finalmente, la Declaración del 48 se aprueba con 48 votos a favor y 8 abstenciones; pero lo importante para nosotros es que introdujo un nuevo gancho trascendental del que colgar los derechos y los deberes: la dignidad. Sobre lo que sea la dignidad nadie lo explica abiertamente. Veamos por ejemplo lo que dice Sánchez Agesta sobre este concepto en la Constitución española: "la afirmación de la dignidad de la persona como fundamento del orden político y de la paz social no tiene en el texto de la Constitución ninguna fundamentación que la refiera a otra cosa que la voluntad de la Nación española"49.

Quizá lo que pasa es que ninguno de los ganchos trascendentales se explicó de forma completa. Por otra parte, Marina se acerca también a la opinión de A. Mc Intyre para quien la noción de derecho humano es una ficción moral, pero esto no lo ve Marina como un reproche sino como un elogio, porque es un hallazgo de la inteligencia creadora. Esta idea de la invención ética es la que le hace afirmar que estamos en una etapa constituyente, es decir, de construcción o de constitución de la ética.

Recapitulando, entonces, diremos que no es fácil dar razón de por qué debemos hacer esto o aquello; hemos encontrado que la respuesta es compleja y además doble, porque incluye los dos tipos de fundamentación: la antropológica y la inductiva histórica. La primera, la antropológica, encuentra su justificación en el análisis del ser humano como ser inacabado y creativo; la segunda nos lo hace desde un punto de vista experimental. Nos vemos abocados así al proceso constituyente de la ética, a una ética progresiva, perseguida y nunca conseguida del todo.

49. SÁNCHEZ AGESTA, Sistema político de la Constitución española de 1978, Editora Nacional, Madrid, 1981, p. 23. 
Empezaremos por recordar algo en lo que tanto hemos insistido: Marina hace el primer gran intento de buscar una fundamentación para la ética que vaya más allá del análisis antropológico ya sea desde la biología, la psicología o la filosofía más estricta y dirigir la mirada a la historia de la vida humana en sociedad.

Una última cuestión que creemos también importante en la aportación de Marina y que es lo suficientemente gráfica como para sintetizar toda su pretendida fundamentación de la ética, se trata de su teoría de los ganchos trascendentales. Un gancho es una especie de percha de la que colgamos las cosas. Marina busca el gancho nuevo del que colgar los derechos y la ética entera. La historia está Ilena de ellos, algunos han funcionado durante un tiempo, otros lo han hecho pero mal. Dios, la naturaleza, el Ilamado sentido común o la razón universal son algunos de estos ganchos.

Un gancho es un axioma ético y Marina lo llama trascendental siguiendo la terminología kantiana porque es algo que nos pertenece, que es a priori y que luego tiene aplicación a la experiencia y al comportamiento en este caso. Tiene una aplicación que está fuera de nosotros. No existe sin nosotros y somos nosotros quienes lo hacemos funcionar. Es necesario encontrar los axiomas de la ética, esos principios que nos harán construir el orbe ético como si fuera una teoría físico-matemática. Marina propone el que mejor puede funcionar y lo llama dignidad, dignidad que no procede de Dios ni de la naturaleza sino de nuestra convicción de constituirnos como una especie dotada de ella. De nuestro interés en afirmarnos como tales porque así funcionamos mejor.

Estamos, pues, ante una teoría que apuesta por el valor intrínseco del ser humano y por la esperanza en él y en la conquista de un orbe ético dominado por el techo de la dignidad. La injusticia no puede ser la última palabra: "debemos luchar para que la humanidad no quede desmoralizada para siempre por los terribles acontecimientos del presente, para que la fe en un futuro feliz de la sociedad, en un futuro de paz y digno del hombre, no desaparezca de la tierra" ${ }^{\prime 50}$.

\section{Valoración final}

Para empezar, hay que valorar positivamente el intento de Marina de encontrar una fundamentación de la ética, así como el de situar el deber ser como una de las tareas más importantes del ser del hombre, siguiendo en esto la tradición de toda la historia de la filosofía iniciada por Platón y continuada sobre todo por Kant. La cuestión más importante está en cómo podemos pasar del ser al deber ser y en justificar el salto necesario para ello. El punto de partida más adecuado es seguramente el análisis antropológico, puesto que del hombre hablamos y él es nuestro

50. HORCKHEIMER, La función social de la filosofía. En Teoría crítica, Amorrortu, Buenos Aires, 1974, p. 289. 
último objetivo. Marina ha apostado por un estudio de toda la urdimbre humana que hace posible el comportamiento deseado. El hecho de ser animales diferentes, vale decir, especialmente inteligentes, nos aboca a ser animales que son dueños de su destino; $y$ aquí es donde aparece el hecho moral como hecho ineludible de la condición humana. Pero el hecho moral, del que buscamos un fundamento, hunde sus raíces en la especial configuración de la inteligencia humana que es capaz de crear posibilidades, proyectar, mejorar lo que antes había.

Por eso hay que tener en cuenta la labor de Marina al buscar las condiciones antropológicas que hacen posible y necesario el hecho moral. Realizando un paralelismo con Kant, se trata de encontrar las condiciones trascendentales del sujeto que hacen posible la ética o mejor, la ciencia de la ética; estas condiciones deben ser, como en Kant, incondicionales. Hace bien Marina en reclamar para la ética un estatus "científico" que estudie estas condiciones que han sido poco a poco aparcadas como temas escasamente relacionados con la antropología filosófica y con la explicación de nuestra conducta. Asuntos como la voluntad, los sentimientos, las emociones, los deseos, las pasiones, el lenguaje, las creencias, el ingenio, la imaginación, la memoria... forman el caldo de cultivo, "la sopa" de Oparin de la que surgirá la vida, en este caso la vida ética. La dimensión moral del hombre es así un hecho que habrá que explicar, pero también un hecho del que habrá que partir. Nietzsche tenía razón al afirmar que la genealogía de la moral es ajena a ella misma. Marina nos muestra que la creación ética tiene un origen que podríamos llamar extraético. Por eso la mayor parte de la obra de Marina se dedica a escudriñar en la naturaleza humana los fundamentos no-éticos que posibilitan la ética. Basta ver los títulos de sus obras para darse cuenta de ello: Elogio y refutación del ingenio, La inteligencia fracasada, El laberinto sentimental, Teoría de la inteligencia creadora, El misterio de la voluntad perdida, Diccionario de los sentimientos...

Marina nos muestra así que la búsqueda del fundamento de la ética está llena de dificultades, porque en primer lugar su fundamentación teórica la tenemos que buscar en factores o capacidades que de por sí no son éticos, lo cual significa que debemos afrontar nuestra condición humana y moral como algo muy complejo y Marina así lo hace. En segundo lugar, aunque la ética es algo que empieza en el propio sujeto, se encuentra con que no puede ser entendida sin el otro sujeto. La ética es intersubjetividad, la condición social del ser humano debe estar presente en nuestra búsqueda y con ella la paradoja humana que ya anunciara Ortega de libertad en la necesidad y necesidad en la libertad. La ética es relación intersubjetiva, lo cual complica aún más nuestro objetivo de fundamentar la ética porque ya no se trata sólo de saber cómo debo ser, sino también de cómo creo que el otro debe ser o de cómo cree el otro que debo ser yo: "El yo se realiza existiendo en el mundo y con los "otros" con los que comparto el mundo...qué será de mí implica qué será de nosotros, ya que mi yo-mi vida, felicidad o mi desdicha- está indisolublemente ligado 
a lo que será -vida, felicidad, desdicha- del otro con el que estoy vinculado y forma parte de mi yo" $\mathrm{O}^{\prime \prime}$.

O sea que buscamos el nacimiento de un gran río que es la ética y lo primero que nos damos cuenta es que este río nace de numerosos manantiales subterráneos. Nos queda ahora seguir su curso hasta la desembocadura. Nos queda ver qué resulta de lo que podemos Ilamar, según Marina, la fundamentación práctica de la ética.

Marina nos ofrece en este punto una visión novedosa porque ve en la fundamentación práctica la mejor fundamentación de la ética. $Y$ es en esto un autor arriesgado que trata de superar la especulación filosófica y está dispuesto a examinar los resultados que hemos obtenido de ella. Y es que la ética es un saber teórico que está ordenado a la práctica. Esta visión nos viene a enseñar que la ética es a la filosofía lo que la tecnología es a la ciencia. Así, la prueba de fuego para la ética no estará en los grandes tratados sino en la historia. Volviendo al símil del río, no bastarán los mapas para encontrarlo, por mucho que éstos nos den una visión global o aérea de por dónde discurre, sino que tendremos que comprobar en qué sitios trae agua y habremos de examinar también la calidad de la misma. Creemos que este tratamiento de la ética para buscar su fundamentación es quizá la mayor aportación de Marina. La ética necesita ser verificada y falsada con experimentos. La historia nos ofrece el laboratorio en el que generaciones anteriores ensayaron modelos de vida, de perfección, de felicidad que es imprescindible examinar con lupa para ver si aportan algo al caudal del río o sólo riegan campos improductivos. Es en esta búsqueda inductiva de las leyes éticas donde encontramos la mayor contribución de Marina: la teoría de los ganchos trascendentales. Hemos de recurrir a la historia para buscar en ella los "axiomas" éticos de los que hemos colgado nuestras actuaciones, buscamos "el ser" del que hacemos pender el "deber ser". Necesitamos un lecho y un cauce firme para hacer nuestro río navegable. Marina nos muestra con su teoría de los ganchos trascendentales que éstos no cuelgan de ningún sitio y que su fundamento no es otro que la creación o la invención humana. En realidad no existen, pero funcionan; hay que ver cuáles funcionan mejor. Uno de ellos, el último descubierto, el que mejor resultados está dando es el de la dignidad como concepto que sintetiza la creación de derechos.

La ética deberá establecer los criterios bajo los cuales ha de examinarse ese funcionamiento. Marina expone que funcionan bien cuando nos aumentan las posibilidades de autonomía y de realización como seres humanos, inteligentes, que se adueñan de su vida, que crean, que son libres, que son felices, que aumentan su capacidad de actuación sobre su dignidad y la de los demás. Mari-

51. AGUIRRE ORAA, J. M., Perspectivas de fundamentación moral, según manuscrito de 2009 entregado por el autor, de un libro cuyo título será Hacia una ética emancipadora. Perspectivas y fundamentos. 
na propone en este recorrido inductivo por el progreso ético unos cuantos hitos históricos que alimentan nuestro optimismo o nuestra esperanza. Echamos en falta, eso sí, alguno como el de la lucha de los movimientos obreros a partir del marxismo, movimientos de los que toda la situación económica y sobre todo social que ha desembocado en el Estado del bienestar son herederos. Así mismo, aunque aparece la lucha contra la pobreza y la miseria como una cuestión primordial contra la que hay que luchar y a la que hay que vencer, no encontramos en la obra de Marina justificaciones o propuestas concretas de actuación, quizá porque considera que este tema es una cuestión más de estrategia política que de invención ética. Pero si, como él deja sentado, fraternidad, reparto de la riqueza, igualdad, compasión, son los valores sobre los que edificamos el edificio ético parece que habrá que ponerse manos a la obra e intentar asentarlos como pilares sobre los que construir el orbe ético de la dignidad.

También merece ser valorado el interés mostrado por Marina en la construcción de una ética universal, así como la visión de la ética como la de una gran obra que está en permanente construcción y reforma. Marina estudia el edificio que tenemos, pero también el que estamos proyectando construir. Es tan importante el pasado como el futuro. En esta apuesta por una ética universal, hoy, que el marxismo y las religiones han perdido gran parte de la autoridad que mantuvieron en el siglo pasado para diseñar el orbe ético, Marina se une a lo que viene siendo una llamada, podríamos decir que general, a partir de la Declaración de los Derechos Humanos. Una Ilamada en la que encontramos a la mayor parte de los filósofos o escuelas filosóficas que se pronuncian sobre este tema: Bertrand Russell, la ética dialógica de J. Habermas, Karl Otto Apel, o Adela Cortina, la filosofía personalista, la ética de la liberación, etc. Nos encontramos así con Marina ante una ética abierta y no cerrada, que debe ser construida con la colaboración de todos porque todos somos responsables de lo que nos está pasando y de lo que nos puede pasar.

Esta sería la valoración que podemos hacer siguiendo una nueva forma de estudiar la inteligencia y sobre todo las capacidades que la conforman, algunas de las cuales, quizás las más importantes, sean los sentimientos, la voluntad, y las ganas de mejorarnos o como él dice "de salir del pantano tirándonos de nuestros propios cabellos" como el fabulador barón de Münchausen. Un ejemplo que le sirve a Marina para confiar en nuestras posibilidades y también para ser exigentes. Los avances tecnológicos conseguidos en poco tiempo: enviar documentos a distancia al instante, mandar imágenes por satélite, viajar a grandes velocidades, hablar por un teléfono sin cable con alguien que está a miles de kilómetros y además verle, realizar intervenciones quirúrgicas en el organismo sin cirugía... cosas que hace cien años sólo se encontraban en la mente de los autores de ciencia-ficción y eran consideradas imposibles, hoy son hechos cotidianos. El voto femenino, la abolición de la esclavitud, el reconocimiento de los derechos de algunos colectivos, la democracia, la enseñanza o la sanidad pública... fueron sueños hasta hace no muchos años. Necesitamos confiar 
en nuestras capacidades y en nuestras propias fuerzas, como el barón, si queremos mejorar nuestra situación, aunque nos parezca imposible.

En definitiva, pues, estamos ante la obra de alguien que, aunque a veces es tachado de divulgador o de poco académico, nos presenta un panorama, por una parte, enriquecedor sobre la motivación y la conducta humana en el que se recupera para la ética la noción de felicidad, de bien y de virtud platónicos y, por otra, esperanzador sobre el futuro orbe en el que queremos y debemos vivir para lograr nuestras aspiraciones.

\section{Bibliografía}

MARINA, J. A., Teoría de la inteligencia creadora, Barcelona, Anagrama, 1993. —,Ética para náufragos, Barcelona, Anagrama, 1995.

-, Crónicas de ultramodernidad, Barcelona, Anagrama, 2000.

- La lucha por la dignidad, Barcelona, Anagrama, 2000. (LLPD).

- Las culturas fracasadas; Anagrama, Barcelona, 2010. (LCF).

ARISTÓTELES, Ética eudemia, Madrid, Alhambra, 1985.

BOBBIO, N., El tiempo de los derechos, Madrid, Sistema, 1991.

COMPTE-SPONVILLE, A., La felicidad, Barcelona, Paidós, 2001.

CORTINA, Adela, Ética mínima; Tecnos, Madrid, 2008, p. 107.

—, Ética de la razón cordial, Ediciones Nobel, Madrid, 2009.

DUSSEL, E. y APEL, K. H., Ética del discurso y ética de la liberación, Madrid, Trotta, 2004.

FERRATER MORA, F. y COHN, P., Ética aplicada, Madrid, Alianza Universidad 1996.

GUISÁN, E., Razón y pasión en ética, Barcelona, Anthropos. 1986.

KANT, I., La fundamentación de la metafísica de las costumbres, Madrid, Santillana, 1996.

—, La idea de una historia universal en sentido cosmopolita. FCE, México, 2006.

ORTEGA Y GASSET, J., ¿Qué es filosofía?, Madrid, Alianza Editorial, 1991.

ROUSSEAU, J. J., El contrato social, Madrid, Alianza Editorial, 1982.

SÁDABA, J., Diccionario de ética, Barcelona, Planeta, 1997.

SARTRE, J. P., El existencialismo es un humanismo, Madrid, Santillana, 1996.

SAVATER, F., Ética para Amador, Barcelona, Ariel, 2002.

—, Política para Amador, Barcelona, Ariel, 1992.

SINGER, P., Ética. Madrid, Taurus, 2002.

VARIOS, Ética laica y sociedad pluralista, Madrid, Editorial Popular, 1993.

ZUBIRI, X., Cinco lecciones de filosofía, Madrid, Alianza Editorial, 1982. 